\title{
La preposición en con los verbos descender y bajar: solidaridades de rección y solidaridades léxicas
}

\author{
Spanish preposition en with the verbs descender and bajar: \\ prepositional selection and co-occurrence preferences
}

\author{
Rafael García Pérez \\ Universidad Carlos III de Madrid \\ rafael.garcia.perez@uc3m.es \\ ORCID iD: https://orcid.org/0000-0002-1183-4700
}

RESUMEN: Aunque la gramática histórica ha revelado un significado direccional para la preposición española en durante el periodo medieval, la rección de esta preposición por parte de los verbos de movimiento no se explica solo por razones semánticas. La comparación de dos sinónimos del español (descender y bajar), que regían tanto la preposición a como la preposición en para indicar un movimiento direccional, muestra que factores como la etimología y los criterios de coocurrencia léxica, en muchos casos ligados a los textos, son importantes a la hora de determinar sus preferencias.

Palabras clave: lengua castellana, gramática histórica, preposición en, verbos de movimiento, rección preposicional.

ABSTRACT: Although Historical Grammar has explained that the Spanish preposition "en" had a directional meaning in the Middle Ages, semantic reasons were not the only factors that explain the choice of this preposition. The comparison of two Spanish synonyms as descender and bajar, which governed the preposition $a$ and the preposition en to express movement in a particular direction, shows that etymology and cooccurrence preferences, often related to types of text, were also important.

Keywords: Spanish language, historical grammar, preposition en, movement verbs, prepositional selection. 


\section{INTRODUCCIÓN}

Puede considerarse clásica la descripción que hacen los estudios gramaticales del uso de la preposición en. La mayoría coincide en afirmar que, frente a la preposición $a$, seleccionada por los verbos de movimiento dado su significado dinámico y direccional, en se ve regida, sobre todo, por verbos estativos debido a su eminente sentido localizador. No obstante, ello no impide la constatación de que existen algunos usos "anómalos" o irregulares según este patrón definitorio. De hecho, la preposición en se emplea con sentido direccional en diversos contextos. Ello se ha tratado de explicar acudiendo a razones sincrónicas, relacionadas con la semántica de la preposición misma; así Trujillo (1971) señala que la preposición en, como entre, expresa "inclusión entre límites". La diferencia entre ambas estaría en que la última requiere la explicitación de esos límites. Pottier (1972: 211), en la misma línea, argumentaba que la preposición en denota interioridad en un doble límite (es decir, "en el interior de los límites"). Roegiest (1977) también planteaba que el uso de la preposición $a$ es propio de contextos direccionales dinámicos, pero el empleo de en es posible cuando el significado del verbo se centra en el punto final del movimiento ${ }^{1}$, punto final definido entre dos límites. En ese sentido, se produciría, sobre todo, con verbos de penetración (entrar, ingresar, penetrar, introducir...).

Esta última aclaración de Roegiest conecta con las explicaciones basadas en las clases de verbos regentes. Para Morera (1988: 147), los verbos que significan movimiento hacia el interior de algo suelen construirse con la preposición en, aunque es consciente de ciertas diferencias dialectales; de hecho, en América y Canarias es frecuente la construcción con la preposición $a$. También De Bruyne (1999) atribuye el uso de la preposición en al valor semántico de penetración de los verbos de movimiento (entrar, ingresar, meter(se), penetrar) y recuerda la misma diferencia dialectal entre España y América. Waluch-de la Torre (2009: 260 y ss.) señala que, si bien la preposición en es la que muestra más rasgos locativos estáticos, aparece en relaciones adlativas dependientes del verbo; se citan así algunas clases de verbos de movimiento estrechamente implicados en esta rección preposicional, como los verbos que expresan contacto físico violento, verbos que denotan interiorización, verbos que significan introducción de un objeto en el agua, verbos que denotan "dejar o hacer que algo vaya a parar a alguna parte", verbos que significan "ascensión con límite final" o verbos que denotan "movimiento con tránsito". Crego (2000: 113) habla de verbos de tipología direccional, que rigen la preposición $a$, pero señala que algunos de ellos rigen "complementos de lugar en" o "precisiones locativas que indican ubicación" y que en ellos "el desplazamiento se encuentra privilegiado

\footnotetext{
${ }^{1}$ Al término del movimiento alude también María Moliner (2012: 54).
} 
al mismo nivel de la localización". La diferencia con los posicionales radica en el hecho de que estos verbos de movimiento direccionales con complementos de ubicación admiten también otros complementos extensionales. Eslava (2012), por su parte, plantea que, en la elección de la preposición (en o $a$ ), con verbos de movimiento que indican penetración, tiene gran relevancia la capacidad del hablante de "conceptualizar el locativo como un contenedor que permite perfilar el cruce del límite y su formalización con la preposición en".

Ahora bien, la rección de la preposición en ha recibido también una interpretación histórica. En ese sentido, se reconoce que estos empleos son, en muchas ocasiones, restos de un estadio de lengua anterior (Gili Gaya, 1954: 254; Trujillo (1971); Corominas y Pascual, 1980-1991², s. v. en; García Miguel, 2006; RAE, 2009: 2266).

En general, la evolución experimentada por el uso de la preposición en a lo largo del tiempo se ha visto como el resultado de una reestructuración del sistema preposicional en su conjunto que, cada vez más, ha asignado el significado direccional a la preposición $a$. Los estudios gramaticales e histórico-gramaticales muestran un uso direccional más amplio de la preposición en heredado del latín in, que podía regir acusativo con idea tanto de límite como de doble límite; en palabras de Hernández Díaz (2006), "el fin o el término de un movimiento real o figurado". Si la erosión de estos usos fue constante, se han conservado aquellos en que "el movimiento se verifica entre los límites" (Trujillo, 1971; García Miguel, 2006) ${ }^{3}$, aunque se postula también la existencia de un "sema de extensión", con el que se alude a un "movimiento que concluye en el límite" (Trujillo, 1971). La RAE (2009: 2266) prefiere unificar estos sentidos (movimiento entre dos límites y movimiento que concluye en el límite) al afirmar, simplemente, que los complementos introducidos por la preposición en denotan "el final de un movimiento o el resultado de un proceso"; se entiende así que puedan incluirse en el mismo grupo ejemplos clásicos como entrar en la casa y ejemplos un tanto más problemáticos, como ingresar en el ejército, precipitarse en el abismo, etc., donde los límites son metafóricos o no están necesariamente trazados.

Es evidente que estas explicaciones gramaticales son de enorme interés para entender la globalidad del fenómeno, pero no permiten apreciar las diferencias cuantitativas y cualitativas en lo que respecta a la capacidad rectora de cada

\footnotetext{
${ }^{2}$ En adelante citaré únicamente las siglas del diccionario: $D E C H$.

${ }^{3}$ Otros trabajos recientes son más explícitos. Mendizábal de la Cruz (2012) señala que, "aunque se relacione con verbos de movimiento, el significado [de la preposición en] siempre es de interioridad sin desplazamiento conceptual en el segundo término, pues el elemento inicial de la relación se percibe como incluido dentro de una realidad espacio-temporal o nocional, sin traspasar sus límites, como en el ejemplo entrar en casa".
} 
uno de los verbos de movimiento en particular. De ahí la necesidad de completar esta información con un estudio lexicológico. De la consulta de los documentos del corpus ${ }^{4}$ se deduce que la rección de la preposición en no ha sido idéntica para todos estos verbos en todos los contextos ni ha experimentado una misma evolución a lo largo del tiempo. La rección preposicional depende, en buena medida, de factores más específicos ligados a cada una de las unidades, como la selección léxica, lo que a su vez no puede separarse de su historia concreta, entendida esta como una combinación de influencias ejercidas por su origen etimológico, su momento de aparición en la lengua, es decir, su capacidad de integración en un sistema ya constituido, pero en proceso de reestructuración, y su mayor o menor éxito en el uso posterior.

En este trabajo me propongo, pues, estudiar la evolución de la preposición en con valor direccional cuando está regida por un grupo muy concreto de verbos de movimiento: bajar y descender. Se trata de verbos que denotan un desplazamiento espacial en el eje vertical y que están unidos por estrechas relaciones semánticas de identidad (sinonimia).

\section{DESCENDER}

1.1. El DECH (s. v. bajar) señala que el verbo bajar, forma popular existente desde los orígenes del idioma, se empleó menos que hoy en la lengua antigua; la razón sería que en un principio convivió con abaxar y con deçerdeçir, variante popular — según su interpretación— del latín vulgar DESCIDISSE. Es cierto que el verbo bajar apenas se empleó antes del siglo XIII ${ }^{5}$, pero, contrariamente a las afirmaciones de estos autores, los corpus nos muestran que no son las formas abaxar ni deçer-deçir las que entran verdaderamente en competencia con él ${ }^{6}$, sino descender (deçendir, deçender), que el DECH (s. v. descender) reconoce como "frecuente en toda la Edad Media", aunque estiman también que se trata de una forma "no enteramente popular". En todo caso, la encontramos, al menos, desde principios del siglo XIII, como una continuación del DESCENDERE latino. Es interesante comprobar que, de modo mayoritario,

\footnotetext{
${ }^{4}$ He utilizado el $C D H$ (corpus del Nuevo diccionario histórico del español) para la elaboración del presente trabajo. He expurgado los textos haciendo una búsqueda en bruto de los lemas base. En el corpus están incluidas todas las variantes gráficas, aunque, como se verá, en este trabajo regularizaré su escritura según las grafías actuales.

${ }^{5}$ Para la competencia entre estos sinónimos y sus repercusiones en el uso, vid. Eberenz (1998).

${ }^{6}$ La importancia que parece conceder el $\mathrm{DECH}$ a deçer-deçir procede de la constatación de que es "el único que figura en el Cid", pero los corpus apenas arrojan ocurrencias. En cuanto a abaxar, su uso transitivo excede con creces al intransitivo pronominal, lo que supone una escasa competencia para bajar.
} 
desde el principio, la preposición regida por este verbo cuando expresa dirección es $a$, siguiendo el modelo general de la lengua romance, pues la lengua antigua, como en nuestros días tendía a discriminar entre usos direccionales y localizadores por medio de las preposiciones $a$ y en. No obstante, la variación es posible $\mathrm{y}$, en los mismos contextos direccionales podemos encontrar la preposición en.

Desde un punto de vista puramente estadístico, la rección de la preposición en por parte del verbo descender se sitúa, sobre todo, en el periodo medieval. No se trata solo de que aumente considerablemente el número total de ejemplos en este periodo ${ }^{7}$, sino también de que crezca su proporción en relación a la preposición $a$. Si comparamos la rección de ambas preposiciones ${ }^{8}$ en el corpus, nos percatamos de que la frecuencia de uso de la preposición en, en cuanto elemento regido por el verbo descender, aumenta considerablemente en el siglo XIV (donde llega a superar a la preposición $a$ ), se mantiene con un leve descenso en el siglo XV, y tiende a desaparecer a partir del siglo XVI, sustituida definitivamente, de ahí en adelante, por la preposición $a$. A partir del siglo XVII, los ejemplos con que contamos son ya muy escasos ${ }^{9}$.

La evolución de la rección de las preposiciones en y a con el verbo descender podría resumirse por medio del siguiente cuadro:

\footnotetext{
${ }^{7}$ Pasamos de una treintena en el siglo XIII a casi ochenta en el siglo XIV y más de ciento setenta en el siglo XV.

${ }^{8}$ Se ha tenido en cuenta, únicamente, la rección explícita de las preposiciones en y a. En ese sentido, se han obviado las ocurrencias en que aparecen simples adverbios de dirección (p. ej. abajo), pues, dado que pueden combinarse con una u otra preposición, su presencia aislada no permite discriminar cuál de ellas se sobreentiende en cada caso.

${ }^{9}$ Hay, eso sí, una cierta concentración en la primera década del seiscientos (lo que sería explicable por una inercia de siglos anteriores). En esa década se concentran ocho de los diez ejemplos totales. Hay que decir que, junto a nombres de lugar o nombres comunes fácilmente interpretables como locativos, encontramos también dos sustantivos abstractos sin un precedente histórico en sentido estricto (error y locura), que responden a la tradicional metáfora cognitiva de los estados configurados en términos espaciales y que, como tales, podrían haberse visto seleccionados debido a una interferencia con el verbo caer, verbo de apoyo metafórico más común desde el siglo XIII (caer en la locura, caer en el error). En los siglos XVIII y XIX los ejemplos son menos abundantes. En el siglo XVIII hay solo dos ejemplos; en el siglo XIX, cuatro, tres de los cuales pertenecen a textos poéticos. Uno de ellos, procedente de un poema de Esteban Echeverría, es ambiguo a mi entender y, por tanto, dudoso. Aunque la preposición sigue al verbo descender, es probable que constituya, más bien, un sintagma locativo dependiente del participio que le sigue: "Y el cielo, y el espacio no formaron / más que un lúgubre, denso, opaco abismo / de tinieblas palpables a mis ojos. / Me estremecí de horror: -formas confusas, / fábricas gigantes del orgullo, / cadáveres inmensos de los siglos, / pueblos, generaciones, seres, hombres, / cual rápido torrente descendían / en la inapelable sima confundidos, / y al caos daban ser..." (1834, Esteban Echeverría, Los consuelos, poesías, ed. Biblioteca Virtual Miguel de Cervantes). También los empleos en el siglo XX tienen una presencia esporádica; son dieciséis en total.
} 


\begin{tabular}{|l|c|c|c|c|}
\hline \multicolumn{1}{|c|}{ Rección (movimiento direccional) } & Siglo XIII & Siglo XIV & Siglo XV & Siglo XVI \\
\hline Descender $a$ & $83 \%$ & $40 \%$ & $58 \%$ & $87 \%$ \\
\hline Descender en & $17 \%$ & $60 \%$ & $42 \%$ & $13 \%$ \\
\hline
\end{tabular}

CUADRO 1.- Rección de la preposición en por el verbo descender entre los siglos XIII y XVI.

Lo que en forma de gráfico podría representarse de la siguiente manera:

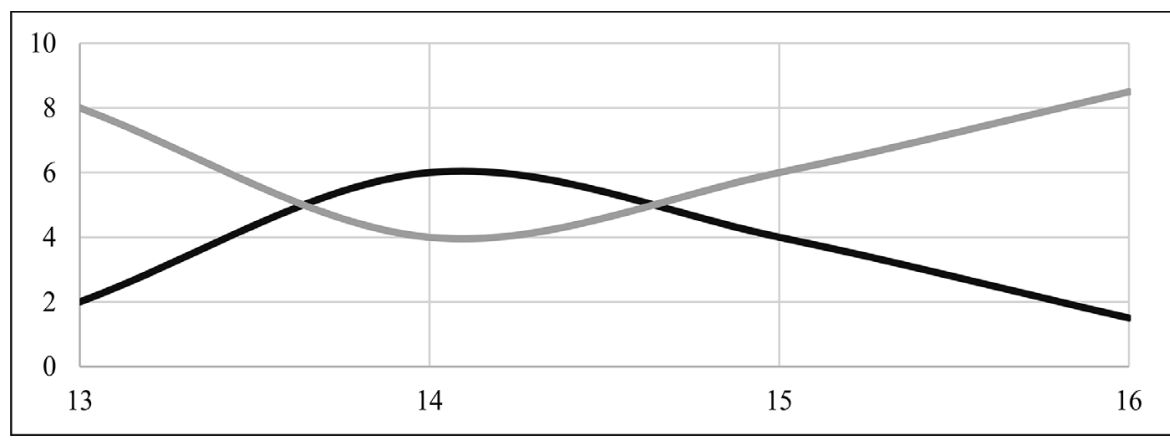

GRÁFICO 1.-Rección de la preposición a (gris) y en (negro) por el verbo descender entre los siglos XIII y XVI.

Este considerable aumento en los siglos finales de la Edad Media podría explicarse si pensamos, como se ha apuntado en el apartado introductorio, que el uso direccional de la preposición en es heredero de la lengua latina; en este idioma, efectivamente, tanto ad como in tenían un mismo sentido direccional, y los siglos XIV y XV se caracterizan en la Península Ibérica por un deseo muy claro de imitación de los textos latinos.

Ahora bien, no basta con comprobar que la preposición en no se distribuye por igual en todos los siglos de la Edad Media, sino que se hace necesario, para entender adecuadamente su empleo, determinar en qué proporción se combina con los sustantivos seleccionados por el verbo descender y cómo evoluciona en estas combinaciones. En principio, muchos de los sustantivos seleccionados por el verbo descender y regidos por la preposición en se hallan también regidos por la preposición $a$. Se trata de un fenómeno que encontramos ya desde el origen de las variedades romances peninsulares. Los primeros ejemplos se remontan al siglo XIII, y pueden rastrearse, muchas veces, incluso dentro de la misma obra, como se puede apreciar en estos ejemplos:

... e si perdiere a Beniamin, descendré en mi veieza en el infierno e plorarlo hé y (c1200 Almerich, La fazienda de Ultra Mar, ed. Moshé Lazar) 
... si este nom adozides, faredes en my veieza decender al infierno mi alma (c1200 Almerich, La fazienda de Ultra Mar, ed. Moshé Lazar)

Estas alternancias en contextos tan similares hacen pensar que nos hallamos ante meras variantes estilísticas. Tanto descender al infierno como descender en el infierno no implicarían una interpretación distinta, aunque quizá la segunda de ellas aportara connotaciones cultas de las que carecería la primera si tenemos en cuenta la tendencia temprana del romance a la distribución de funciones y significados. Otra cuestión es determinar si sería posible, además, atribuir una idea de interiorización a la preposición en (inconcebible en el caso de la preposición a) cuando el sustantivo se presta a ello, es decir, cuando este designa una realidad comprendida entre dos límites. No es descartable, sobre todo si tenemos en cuenta que ese sentido había existido en su étimo in, si bien se trataría de una posibilidad meramente contextual ${ }^{10}$. Pensemos en casos como el siguiente:

... ca ellos pusieron en el río de Aniene (que descendía en la cibdat de Sabina) grant quantidat de madera, la qual ellos pusieron atada en uno toda e ligada (c1400, Pero López de Ayala, Traducción de las Décadas de Tito Livio ed. Curt J. Wittlin).

El corpus nos muestra que, durante esta misma centuria (siglo XIII), los sustantivos seleccionados por las preposiciones $a$ y en no se oponen (o no necesariamente) por su designación de realidades caracterizadas por su mayor o menor delimitación; las dos son capaces de seleccionar, indistintamente, nombres propios de lugar (países o ciudades) y nombres comunes de sentido locativo no cerrados (campo, prado, valle...).

Labán el siriano segudava a mio padre, por que ovo a decender en Egipto, e fue allá peregrino con muy pocos... (c1275, Alfonso X, General Estoria, Primera parte, ed. Pedro Sánchez-Prieto Borja)

E del año en que Jacob a Egipto descendió fasta"l año en que Josep finó ovo setaenta años... (c1275, Alfonso X, General Estoria, Primera parte, ed. Pedro Sánchez-Prieto Borja)

E desque fueron llegados, descendieron en el campo do él estaba (a1300, Anónimo, El caballero del cisne, ed. Louis Cooper).

... por tal si ellos por alguna manera o fecho pudiessen echar a los romanos del vallado en que estauan metidos et fazerlos exir et descender a los cam-

${ }^{10}$ Lo que queda lejos de ser automático. García Miguel (2006) parece plantear una oposición esencial entre aproximación $(a d)$-interiorización (in) en latín que no se da en todos los casos. Es cierto que in + acusativo podía indicar movimiento entre dos límites, pero también simple movimiento hacia el límite, como demuestran los ejemplos ya clásicos de Butler (1823: 132 y ss.). 
pos planos (1376-1396, Juan Fernández de Heredia, Traducción de la Historia contra paganos, de Orosio, ed. Juan Manuel Cacho Blecua).

Aceptando la posibilidad de que, como señalaba la RAE (2009: 2266), la preposición en denotara el final del movimiento frente al movimiento mismo (propio de la preposición $a$ ), la rección de ambas preposiciones por el verbo descender depende, sobre todo, de otros factores que no se han tomado suficientemente en consideración, como el sustantivo seleccionado, el tipo de texto en que aparece la combinación léxica y los usos heredados de la lengua latina.

Conviene señalar que, en el caso de algunos sustantivos, el uso de la preposición $a$ supera con creces, en frecuencia, al uso de la preposición en, que mantiene un empleo relativamente marginal durante todo el periodo medieval. Esto resulta especialmente significativo en lo que se refiere a sustantivos de alta frecuencia y dispersión en el corpus ${ }^{11}$, lo que parece indicar una clara preferencia de los hablantes a lo largo del tiempo y, en consecuencia, una estrecha solidaridad verbo-preposición-sustantivo: infierno, por ejemplo, el más abundante de todo el corpus, con más de doscientas ocurrencias en más de cincuenta obras (entre los siglos XIII y XVI) ${ }^{12}$, solo presenta dos usos con la preposición en en el siglo XIII, cuatro en el siglo XIV, uno en el siglo XV y ninguno ya a partir del siglo XVI. La ruptura del patrón descender $+a+$ infierno podría considerarse meramente anecdótica. La solidaridad entre los tres elementos es más significativa aún si pensamos que otros verbos que seleccionan complementos direccionales y que están enormemente extendidos en la lengua (ir, caer) no seleccionan con tanta frecuencia el sustantivo infierno. La rección de la preposición $a$, más adecuada al patrón romance, es más antigua de lo que podríamos suponer, pues la encontramos ya en los textos latinos medievales peninsulares que, a su vez, no hacen sino continuar un uso clásico; los autores latinos seleccionaban esta preposición de modo casi exclusivo ${ }^{13}$. Otros sustantivos que muestran una preferencia por la preposición $a$-de frecuencia y dispersión medias - son los siguientes (ordenados de mayor a menor solidaridad rectiva, medida en porcentajes):

${ }^{11}$ Con la frecuencia hago referencia, claro está, al número de ocurrencias; con la dispersión, al número de obras diferentes en que aparecen esas ocurrencias.

${ }^{12}$ Las ocurrencias son directas; no tomo en consideración los ejemplos en que los sustantivos son complemento de otro sustantivo nuclear, pues es este el que es objeto de selección (fondo del infierno, p. ej.). En cuanto a las obras con el mismo título, aunque publicadas en distintas partes, las cuento como una sola.

${ }^{13}$ El CORDE arroja, para los textos anteriores al siglo XII, seis ocurrencias en que el verbo descendere rige la preposición ad al seleccionar el sustantivo infernum (inferna en plural) y una sola ocurrencia en que rige la preposición in. En latín clásico, se usaba, sobre todo, el plural inferi (de inferus), combinado con la preposición $a d$, como se desprende, por ejemplo, de la consulta del corpus Classical Latin Texts (PHI). 


\begin{tabular}{|l|c|c|c|c|c|c|}
\hline Sustantivo & $\begin{array}{c}\text { Total } \\
\text { ocurrencias } \\
\text { (ss. XIII-XVI) }\end{array}$ & $\begin{array}{c}\text { Obras } \\
\text { distintas }\end{array}$ & $\begin{array}{c}\text { Prep. } \\
a\end{array}$ & $\begin{array}{c}\text { Prep. } \\
\text { en }\end{array}$ & $\begin{array}{c}\text { Porcentaje } \\
\text { prep. } a\end{array}$ & $\begin{array}{c}\text { Porcentaje } \\
\text { prep. } \text { en }\end{array}$ \\
\hline abismo & 17 & 10 & 17 & 0 & 100 & 0 \\
\hline llano & 35 & 21 & 34 & 1 & 97,2 & 2,8 \\
\hline limbo & 18 & 10 & 17 & 1 & 94,5 & 5,5 \\
\hline casa & 17 & 12 & 15 & 2 & 88,3 & 11,7 \\
\hline río & 15 & 13 & 11 & 2 & 86,7 & 13,3 \\
\hline valle & 24 & 22 & 19 & 5 & 79,2 & 20,8 \\
\hline ribera & 13 & 8 & 8 & 3 & 77 & 23 \\
\hline lago & 20 & 10 & 13 & 7 & 65 & 35 \\
\hline campo & 9 & 8 & 5 & 4 & 55,5 & 44,5 \\
\hline
\end{tabular}

CUADRO 2.-Muestra de la selección léxica y la rección preposicional del verbo descender.

En el caso de los sustantivos abismo y limbo nos encontramos con solidaridades léxicas equivalentes a la que acabamos de ver para infierno, lo que, en principio, no sería de extrañar porque ambos se ven seleccionados por el verbo descender en el mismo contexto religioso. Si limbo tiene una estrecha conexión semántico-referencial con el sustantivo infierno (el limbo era una región situada en los bordes del infierno), abismo entra con este sustantivo, en los mismos textos eclesiásticos, en relación sinonímica.

En cuanto a los sustantivos que designan lugares comunes abiertos, la selección y la rección parecen estar muy relacionadas con el carácter más o menos popular del sustantivo y su conexión con un étimo latino. El sustantivo llano, claramente popular y sin equivalente de uso en su étimo latino, se ve seleccionado por el verbo descender y la preposición $a$, y lo hace casi de modo exclusivo. Su combinación con la preposición en es meramente anecdótica (el corpus arroja un solo ejemplo) y se produce en un momento en que esta preposición, como hemos visto, se halla en franca decadencia. Es muy probable que se trate de un empleo marcadamente literario o, en todo caso, meramente extranjerizante, lo que se deduciría del tipo de texto en que aparece: la traducción de Orlando el Furioso de Jerónimo de Urrea. Otros sustantivos, como valle y campo, cuyos étimos latinos aparecían indistintamente con las preposiciones ad e in en los textos clásicos, admiten, como se puede apreciar en el cuadro, la preposición en con mayor frecuencia durante buena parte del periodo medieval y, preferentemente, en los siglos XIV y XV, aun cuando no lleguen a superar a la preposición $a$. Es interesante destacar que estos usos con la preposición en se corresponden, muchas veces, con traducciones de textos italianos o latinos.

Precisamente, ciertos modelos y los tipos de textos pueden inducir determinados usos. Es lo que sucede con el sustantivo lago que, en combinación con el verbo des- 
cender, suele traducir en los textos medievales eclesiásticos la expresión latina in lacum descendere (con el sentido de 'morir'). De ahí la relativamente alta proporción en la que el verbo español descender rige también la preposición en. Lo mismo puede decirse del sustantivo huesa ( $<$ FOSSA), que parece responder a la combinación latina in fossam descendere, con idéntico significado ${ }^{14}$, y que apenas se usa con la preposición $a$ en el periodo medieval, como se puede apreciar en el siguiente cuadro ${ }^{15}$ :

\begin{tabular}{|l|c|c|c|c|c|c|}
\hline Sustantivo & $\begin{array}{c}\text { Total } \\
\text { ocurrencias } \\
\text { (ss. XIII-XVI) }\end{array}$ & $\begin{array}{c}\text { Obras } \\
\text { distintas }\end{array}$ & $\begin{array}{c}\text { Prep. } \\
a\end{array}$ & $\begin{array}{c}\text { Prep. } \\
\text { en }\end{array}$ & $\begin{array}{c}\text { Porcentaje } \\
\text { prep. } a\end{array}$ & $\begin{array}{c}\text { Porcentaje } \\
\text { prep. en }\end{array}$ \\
\hline huesa & 5 & 3 & 1 & 4 & 20 & 80 \\
\hline
\end{tabular}

CUADRO 3.--Rección preposicional del verbo descender con el sustantivo huesa.

La influencia latina actúa también de modo más selectivo. Es lo que parece suceder con los topónimos que designan nombres de países. Mientras el sustantivo Egipto, muy abundante en los textos religiosos, muestra una clara preferencia por la preposición $a$, el sustantivo Italia, de clara raigambre clásica, se combina con la preposición en cuando es seleccionado por el verbo descender. En ello hay que ver, quizás, la inercia de ciertos textos clásicos latinos, sobre todo de carácter historiográfico ${ }^{16}$, tanto más cuanto que las ocurrencias que arroja el corpus son todas posteriores al siglo XIII y desaparecen a partir del siglo XVII.

\begin{tabular}{|l|c|c|c|c|c|c|}
\hline Sustantivo & $\begin{array}{c}\text { Total } \\
\text { ocurrencias } \\
\text { (ss. XIII-XVI) }\end{array}$ & $\begin{array}{c}\text { Obras } \\
\text { distintas }\end{array}$ & $\begin{array}{c}\text { Prep. } \\
\text { a }\end{array}$ & $\begin{array}{c}\text { Prep. } \\
\text { en }\end{array}$ & $\begin{array}{c}\text { Porcentaje } \\
\text { prep. } a\end{array}$ & $\begin{array}{c}\text { Porcentaje } \\
\text { prep. en }\end{array}$ \\
\hline Egipto & 63 & 20 & 49 & 14 & 77,8 & 22,2 \\
\hline Italia & 7 & 5 & 0 & 7 & 0 & 100 \\
\hline
\end{tabular}

CUADRO 4.--Rección preposicional del verbo descender con los sustantivos Egipto e Italia.

${ }^{14}$ Se trata, pues, de estructuras con un alto grado de fijación.

15 En este caso, dado el escaso número de ocurrencias, es significativo el alto porcentaje que corresponde a la rección con la preposición en.

${ }^{16}$ El corpus Classical Latin Texts (PHI) confirma la rección de la preposición in por parte del verbo descendere con el topónimo Italia en acusativo, no tanto porque el número de ejemplos sea especialmente grande, sino, sobre todo, por el hecho de que no aparece ningún ejemplo en que el verbo rija la preposición ad + acusativo. La rección de la preposición in aparece en Titus Livius, Periochae Librorum A. U. C. 21.1. y Titus Livius, Ab Urbe Condita, 21.44.1.1). Esta selección estaba en consonancia con otros topónimos similares de gran tradición en los textos clásicos. Así, con el sustantivo Graecia 'Grecia', los textos latinos muestran una rección con la preposición in + acusativo, pero no con la preposición $a d+$ acusativo (Cornelius Nepos, Vitae, Ar.1.1.1. y Titus Livius, $A b$ Urbe Condita, 27.30.1.1). Lo mismo puede decirse del sustantivo Gallia (Gaius Sallustius Crispus, Catilinae Coniuratio, 57.1.1). 
Especialmente interesante es la selección, por parte del verbo descender, del sustantivo tierra. El número de ocurrencias es bastante elevado, aun cuando algunas obras contribuyan particularmente a elevar ese número. Como se ve en el cuadro siguiente, las combinaciones con la preposición en superan a las combinaciones con la preposición $a$.

\begin{tabular}{|l|c|c|c|c|c|c|}
\hline Sustantivo & $\begin{array}{c}\text { Total } \\
\text { ocurrencias } \\
\text { (ss. XIII-XVI) }\end{array}$ & $\begin{array}{c}\text { Obras } \\
\text { distintas }\end{array}$ & $\begin{array}{c}\text { Prep. } \\
a\end{array}$ & $\begin{array}{c}\text { Prep. } \\
\text { en }\end{array}$ & $\begin{array}{c}\text { Porcentaje } \\
\text { prep. } a\end{array}$ & $\begin{array}{c}\text { Porcentaje } \\
\text { prep. en }\end{array}$ \\
\hline tierra & 149 & 61 & 62 & 87 & 41,6 & 58,4 \\
\hline
\end{tabular}

CUADRO 5.--Rección preposicional del verbo descender con el sustantivo tierra.

Una consulta más detenida de los datos del corpus muestra que la selección del sustantivo por el verbo descender corresponde, en la mayor parte de los casos, a la idea de 'tomar tierra' o 'poner el pie en el suelo', lo que suele manifestarse en la ausencia de artículo (descender alen tierra).

\& enuio rogar a la Reyna que descendiesse a tierra. \& folgarie algunos días fasta que sopiesse nueuas del Rey so hermano (1293, Anónimo, Gran Conquista de Ultramar, ed. Louis Cooper/Franklin M. Waltman, Madison).

Et, aqui ueyendo que la terra era bella, deçendio en terra con toda su gent... (1377-1393, Juan Fernández de Heredia, Crónica de Morea ed. Juan Manuel Cacho Blecua).

De hecho, las estructuras a tierra y en tierra presentan un alto grado de fijación. Si la selección de la preposición en es mucho más frecuente que la selección de la preposición $a$, esta mayor frecuencia se concentra, sin embargo, en los siglos XIV y XV; los siglos XIII y XVI, pueden interpretarse como preludio y colofón, respectivamente, de esta gran tendencia tardomedieval. Así, en el siglo XIII encontramos una sola ocurrencia en la que el verbo descender rige la preposición en cuando selecciona el sustantivo tierra, y lo hace con el significado general composicional de 'desplazarse hacia la tierra' (no es de extrañar, pues, que el sustantivo tierra aparezca precedido del artículo ${ }^{17}$ ) y, en el siglo $\mathrm{XVI}$, solo siete ocurrencias (seis de ellas con la idea de 'tomar tierra', restos del empleo de los dos siglos anteriores). A partir del siglo XVII solo contamos con la estructura descender a tierra, más acorde con el reparto de funciones que el

${ }^{17}$ El ejemplo es, además, problemático porque, como señala la datación del corpus, podría tratarse de un uso de principios del siglo XIV: “...e como la gota del rucio de la mañana que decende en la tierra e se seca luego a la primera vista del sol" (a1280 [finales del s. XIII o principios del s. XIV] Alfonso X, General Estoria. Tercera Parte. Libros de Salomón: Cantar de los cantares, Proverbios, Sabiduría y Eclesiastés, ed. Pedro Sánchez-Prieto Borja/Bautista Horcajada Diezma). 
español ha tendido a atribuir, desde el principio, a las preposiciones $a$ y en. Es la estructura que, ya con carácter arcaizante, encontramos también en nuestros días. La selección, durante los siglos XIV y XV, del sintagma en tierra y su estrecha solidaridad con el verbo descender, responde, sin duda, a un gusto culto propio de los textos escritos.

\section{BAJAR}

Ya se ha apuntado en el apartado precedente que el verbo bajar, evolución del latín vulgar *BASSIARE, derivado a su vez de BASSUS, es una forma enteramente popular que encontramos desde los orígenes del idioma $(D E C H, s$. $v$. bajar), ya con la idea de 'moverse hacia un lugar bajo o más bajo' ( $D H$, s. v. bajar). Con el mismo origen etimológico encontramos la variante abajar ( $<\mathrm{AD}$ BASSIARE), fundamentalmente transitiva y reflexiva ( $D E C H, s . v$. bajar), aunque ello no excluye algunos empleos intransitivos que será necesario tomar en consideración. De ahí que en este trabajo prefiera tratar ambas formas conjuntamente.

Ahora bien, como también he señalado en el apartado anterior, ni bajar ni abajar son las formas más usadas en la lengua antigua, especialmente en la acepción intransitiva de desplazamiento, pues desde muy temprano entraron en competencia con una forma de mayor éxito: descender. Los datos del corpus muestran una preponderancia de descender hasta el siglo XVI y un aumento progresivo en el uso de la forma bajar a partir de esa misma centuria; ello supone que se produzca una caída de la forma descender, que de ese modo ha acentuado - si aceptamos la idea del $D E C H$ acerca de su carácter "no enteramente popular" ( $D E C H$, s. $v$. descender) - su connotación culta. El siguiente cuadro ${ }^{18}$ muestra el gran impulso que recibe el verbo (a)bajar a partir del Renacimiento:

\begin{tabular}{|l|c|c|c|c|c|}
\hline & \multicolumn{5}{|c|}{$\mathrm{N}^{\text {o }}$ de ocurrencias / Porcentaje de uso (\%) } \\
\hline \multirow{2}{*}{ (a)bajar } & & s. XIII & s. XIV & s. XV & s. XVI \\
\hline \multirow{2}{*}{ Preposiciones } & $a$ & $33 / 94,3$ & $6 / 66,7$ & $104 / 88,9$ & $754 / 94,25$ \\
\cline { 2 - 7 } & en & $2 / 5,7$ & $3 / 33,3$ & $13 / 11,1$ & $44 / 5,75$ \\
\hline
\end{tabular}

CUADRO 6.-Uso del verbo (a)bajar entre los siglos XIII y XVI.

Es muy significativo comprobar, además, que el verbo bajar no solo se usa en menor proporción que el verbo descender a lo largo del periodo medieval,

\footnotetext{
18 Tomo en cuenta las formas bajar y abajar, tanto en su uso transitivo como intransitivo, siempre que presenten un sentido direccional.
} 
momento álgido en lo que respecta a la rección de la preposición en, sino que sus criterios de rección y selección léxica no son equivalentes a los de su sinónimo, aun cuando ambos hayan recorrido la misma trayectoria a lo largo de la historia de nuestra lengua.

En primer lugar, la rección de la preposición $a$ por parte del verbo bajar supera, durante todo el periodo medieval, a la de la preposición en, y ello independientemente del sustantivo seleccionado y del contexto. El porcentaje es, además, especialmente alto en todo momento, a pesar del aumento significativo en el uso de la preposición en durante el siglo XIV.

Podemos decir, pues, que el verbo (a)bajar se ha adaptado con mayor rigor a la distribución de significados y funciones que el castellano había empezado a instaurar en el uso de las preposiciones $a$ y en. Quizá haya que ver en ello un resultado de la connotación más popular de este verbo, sin equivalente formal en latín clásico; su carácter menos permeable a los usos cultos introducidos en los siglos finales de la Edad Media se acentuaría, en parte, por la mayor permeabilidad de su sinónimo descender, para el que los escritores medievales encontraron modelos directos de rección en su étimo formal DESCENDERE.

En segundo lugar, si comparamos los sustantivos seleccionados por el verbo (a)bajar con los sustantivos seleccionados por el verbo descender, percibimos algunas singularidades. Veamos el siguiente cuadro ${ }^{19}$ :

\begin{tabular}{|l|c|c|c|c|c|}
\hline $\begin{array}{l}\text { Sustantivos (por } \\
\text { orden de } \\
\text { frecuencia) }\end{array}$ & $\begin{array}{c}\text { Total ocurrencias } \\
\text { (ss. XIII-XVI) }\end{array}$ & $\begin{array}{c}\text { Prep. } \\
a\end{array}$ & $\begin{array}{c}\text { Prep. } \\
\text { en }\end{array}$ & $\begin{array}{c}\text { Porcentaje } \\
\text { prep. } a\end{array}$ & $\begin{array}{c}\text { Porcentaje } \\
\text { prep. } \text { en }\end{array}$ \\
\hline tierra & 119 & 99 & 20 & 83,2 & 16,8 \\
\hline llano & 88 & 85 & 3 & 96,5 & 3,5 \\
\hline suelo & 86 & 82 & 4 & 95,3 & 4,7 \\
\hline infierno & 65 & 64 & 1 & 98,5 & 1,5 \\
\hline valle & 38 & 38 & 0 & 100 & 0 \\
\hline río & 29 & 29 & 0 & 100 & 0 \\
\hline limbo & 12 & 12 & 0 & 100 & 0 \\
\hline abismo & 9 & 9 & 0 & 100 & 0 \\
\hline italia & 7 & 3 & 4 & 42,8 & 57,2 \\
\hline campo & 5 & 5 & 0 & 100 & 0 \\
\hline casa & 5 & 5 & 0 & 100 & 0 \\
\hline ribera & 4 & 4 & 0 & 100 & 0 \\
\hline lago & 1 & 1 & 0 & 100 & 0 \\
\hline
\end{tabular}

CUADRO 7.--Muestra de la selección léxica y la rección preposicional del verbo (a)bajar.

${ }^{19}$ El cuadro no recoge todos los sustantivos, sino solo los más utilizados y aquellos que también seleccionaba el verbo descender. 
Como se desprende de los datos, la mayor parte de los sustantivos son seleccionados, claramente, por la preposición $a$, lo que corresponde a esa tendencia general del verbo a adaptarse a los nuevos significados y valores preposicionales de la lengua romance. Los porcentajes son especialmente altos, incluso en aquellos casos en que el verbo descender había aceptado la rección de la preposición en por inercia latina (valle, campo, río). Es especialmente interesante destacar que el sustantivo lago no se ve seleccionado en ningún momento por el verbo bajar con el sentido de 'morir', como sucedía con descen$d e r^{20}$; de ahí que resulte fácilmente explicable su escasa frecuencia de uso y el recurso a la preposición $a$. Algunos sustantivos seleccionados por descender cuando regía la preposición en ni siquiera tienen presencia en el corpus como complementos de bajar. Es el caso, por ejemplo, del sustantivo huesa.

Aunque el cuadro nos muestra que el sustantivo tierra presenta un porcentaje relativamente más alto de ocurrencias cuando el verbo bajar rige la preposición en que el resto de los vocablos, queda bastante lejos del porcentaje que representaba su selección por parte del verbo descender; en efecto, la selección del sustantivo tierra cuando descender regía la preposición en, como hemos visto, superaba claramente a su selección cuando el verbo regía la preposición $a$. Recordemos que en ello había tenido mucho peso la difusión por la lengua de la expresión descender en tierra con la idea de 'tomar tierra' o 'poner los pies en suelo firme'. De hecho, en el corpus son numerosos los ejemplos de este uso en contextos en los que alguien desciende de algún medio de transporte (caballo, barco, etc.). En lo que se refiere a bajar, esta expresión, con ese significado contextual, tanto si rige la preposición $a$ como si rige la preposición en ((a)bajar a tierra / (a)bajar en tierra), es residual ${ }^{21}$ en ese momento en que alcanza su apogeo el uso con el verbo descender (ss. XIV y XV), lo que demuestra con cuánta fuerza los hablantes pueden ligar una forma y un significado. La mayor parte de los usos en que el verbo bajar selecciona el sustantivo tierra transmiten el significado composicional de 'moverse en dirección de un lugar' y responden a un empleo transitivo del verbo (destacan, sobre todo, los ejemplos de (a)bajar los ojos, el rostro, etc. en dirección a la tierra $)^{22}$.

E todos los que esto mobistes baxad las cabeças a tierra e parad los cuellos, ca descabeçados seredes agora (1471-1476, Lope García de Salazar, Istoria de las bienandanzas e fortunas, ed. Ana María Marín Sánchez).

${ }^{20}$ En la primera mitad del siglo XVII encontramos un ejemplo en el que lago se refiere a la región de los muertos, pero no hay un significado de 'morir' en sentido estricto: “¿Qué necesidad tenemos (prosiguió) de bajar al averno lago ni de traspalar huesos de difuntos para conocer los vicios? (1636, Cosme Gómez de Tejada, León prodigioso ed. Víctor Arizpe/Abraham Madroñal).

${ }^{21}$ En concreto, dos ocurrencias.

${ }^{22}$ Con la variante abajar es muy frecuente también el sentido metafórico de 'humillar(se)'. 
Cuando se Amadís oyó loar de su señora, baxó los ojos a tierra, que sólo catar no la osava (1482-1492, Garci Rodríguez de Montalvo, Amadís de Gaula, libros I y II, ed. Juan Manuel Cacho Blecua).

A partir del siglo XVI, como es esperable, la expresión bajar a tierra, con ese sentido de 'tomar tierra' o 'pisar suelo firme' empezó a adquirir preponderancia y se impuso a su sinónimo descender en tierra, que tanto predicamento había tenido anteriormente; de hecho, esta rección de la preposición en por el verbo descender no ha dejado rastros desde el siglo XVII. Descender, arrastrado por la fuerza de la distribución general de significados y funciones entre las preposiciones, pasará a regir solo la preposición $a$ y se equiparará así a su sinónimo bajar (descender a tierra / bajar a tierra).

El único sustantivo que rompe con lo esperable en lo que se refiere a los criterios de rección del verbo bajar, es el topónimo Italia $^{23}$. Como nos muestra el cuadro, su selección por medio de la preposición en supera a la correspondiente por medio de la preposición $a$. Dos datos es necesario tener en cuenta a este respecto. En primer lugar, esta selección es muy tardía, pues solo encontramos ejemplos desde el siglo XVI; en segundo lugar, la selección de este sustantivo por medio de la preposición en se prolonga durante los primeros decenios del siglo $\mathrm{XVII}^{24}$ y nada más.

... en fabor del emperador Maximiliano, que en el año siguiente determinaua de baxar en persona en Italia, como por dar calor en las conquistas y guerras de Africa (c1525, Anónimo, Continuación de las Memorias del reinado de los Reyes Católicos de Andrés Bernáldez, ed. Manuel Gómez-Moreno/Juan de Mata Carriazo).

Entrado ya el verano de este año de 1523, sonaban tanto las armas que decían que aparejaba el rey de Francia para bajar en Italia con ánimo de cobrar a Milán y conquistar a Nápoles (1604-1618, fray Prudencio de Sandoval, Historia de la vida y hechos del Emperador Carlos V, ed. Universidad de Alicante).

A partir de ese momento, ya solo encontramos la preposición $a$. Se trata, pues, de un periodo de tiempo muy limitado. La explicación se halla, sin duda, en la inercia del uso clásico transmitido a los textos cultos, como hemos visto, por la variante castellana descender en un momento (s. XVI) en que bajar está cobrando fuerza y la distribución de significados y funciones entre las preposiciones aún no se ha completado. En ese sentido, se puede decir que es el único caso en que se produce una verdadera contaminación entre los empleos de descender y bajar.

\footnotetext{
${ }^{23}$ Los restantes topónimos que designan nombres de países y ciudades no plantean este problema, pues son seleccionados, en bastante mayor proporción, por medio de la preposición $a$.

${ }^{24}$ Con especial abundancia en la Historia de la vida y hechos del emperador Carlos $V$ de fray Prudencio de Sandoval, de la que proceden casi todas las ocurrencias; una ocurrencia más encontramos en la Historia de Felipe II, rey de España, de Luis Cabrera de Córdoba. Ambos, por su nacimiento, son herederos de los usos lingüísticos del siglo XVI.
} 


\section{CONCLUSIÓN}

En el presente trabajo se ha puesto de manifiesto que la rección de la preposición en en la lengua antigua por parte de los sinónimos descender y bajar no resulta equiparable, a pesar de que, como ha señalado la gramática, esta preposición contenía un significado direccional susceptible de afectar a todos los verbos de movimiento. Las diferencias en la rección se deben a razones históricas.

Aunque los dos verbos se emplearon en castellano desde el origen, descender fue, durante todo el periodo medieval, la forma más difundida; solo a partir del siglo XVI se produce un aumento considerable en el uso de la forma bajar que supone una inversión de la tendencia dominante en épocas anteriores. Hemos de tener en cuenta, además, que descender era la forma directamente heredada del latín clásico DESCENDERE, lo que le dio siempre una cierta connotación culta. De ahí que en el periodo álgido de influencia de los textos latinos, es decir, en el llamado "otoño de la Edad Media", descender admitiera con facilidad una parte de la rección propia de su étimo latino y llegara a seleccionar en una alta proporción determinados sustantivos por medio de la preposición en; en algunos casos, incluso, llegó a superar a la realizada por medio de la preposición $a$. Ello afectó especialmente a estructuras sintagmáticas que calcaban expresiones latinas con un cierto grado de fijación o simples solidaridades léxico-rectivas de gran extensión en los textos latinos.

El verbo bajar, por su parte, dado su carácter enteramente patrimonial, se adaptó desde muy temprano al nuevo significado que la lengua romance atribuía a las preposiciones $a$ y en (dirección vs locación), lo que favoreció la rección abrumadora de la preposición $a$. Solo en un caso aislado encontramos un uso divergente de la preposición (el topónimo Italia); este uso, tardío y muy reducido en el tiempo, se explicaría por una interferencia particular entre los textos cultos.

En definitiva, los datos aportados por este trabajo confirman que el sistema de rección preposicional es tanto o más una cuestión léxico-gramatical de carácter histórico que puramente gramatical. Tener en cuenta las conexiones entre las unidades léxicas predicativas y las preposiciones regidas por ellas a la hora de seleccionar sus argumentos, así como los avatares de la historia, resulta fundamental si se quiere dar cuenta, de modo más riguroso, de la evolución del léxico de una lengua.

\section{FUENTES EN LÍNEA}

Instituto de Investigación Rafael Lapesa de la Real Academia Española (2013): Corpus del Nuevo diccionario histórico $(C D H)$ [en línea], <http://web.frl.es/CNDHE> [Consulta: octubre de 2017]. 
Packard Humanities Institute (PHI): Classical Latin Texts [en línea], <http://latin.packhum.org> [fecha de consulta: octubre de 2017].

Real Academia Española: Banco de datos (CORDE) [en línea]; Corpus diacrónico del español, $<$ http://www.rae.es $>$ [fecha de consulta: octubre de 2017].

\section{BIBLIOGRAFÍA}

Butler, Samuel (1823): A Praxis on the Latin Prepositions, Being an Attempt to Illustrate their Origin Signification and Government in the Way of Exercise, London, Longman.

Corominas, Joan y José Antonio Pascual (1980-1991): Diccionario crítico etimológico castellano e hispánico (DECH), Madrid, Gredos.

Crego García, M. V. (2000): El complemento locativo en español. Los verbos de movimiento y su combinatoria sintáctico-semántica, Lalia, Series Maior 12, Santiago de Compostela.

De Bruyne, Jacques (1999): "Las preposiciones" en Ignacio Bosque y Violeta De Monte (dirs.), Gramática descriptiva de la lengua española, Madrid, Espasa-Calpe, pp. 657-703.

Eberenz, Rolf (1998): "Tornar - volver y descender - bajar, orígenes de dos relevos léxicos", en Actas del IV Congreso Internacional de Historia de la Lengua Española, Logroño, Universidad de La Rioja, vol. 2, pp. 109-125.

Eslava Heredia, Cristina (2012): "La alternancia de las preposiciones 'en/a' en verbos de movimiento que denotan penetración en el español de México", Nueva Revista de Filología Hispánica, 60, 2, pp. 425-446, <https://doi.org/10.24201/nrfh.v60i2.1055>.

García Miguel, J. M. (2006): "Los complementos locativos", en Concepción Company (dir.), Sintaxis histórica de la lengua española, México, Universidad Nacional Autónoma de México, pp. 1253-1336.

Gili Gaya, Samuel (1954): Curso superior de sintaxis española, Barcelona, Vox.

Hernández Díaz, Axel (2006): "Las preposiciones en y entre", en Concepción Company (dir.), Sintaxis histórica de la lengua española, México, Universidad Nacional Autónoma de México, pp. 1629-1722.

Mendizábal de la Cruz, Nieves (2012): "Valores semánticos de la preposición en: el caso del español de México en un corpus de entrevistas orales", AnMal Electrónica, 33, <http:// www.anmal.uma.es/numero33/Preposiciones_Mexico.pdf $>$.

Moliner, María (2012): Uso de las preposiciones, Madrid, Gredos.

Morera Pérez, Marcial (1988): Estructura semántica del sistema preposicional del español moderno y sus campos de usos, Puerto del Rosario, Excmo. Cabildo insular de Fuerteventura.

Pottier, Bernard (1972): Introduction à l'étude linguistique de l'espagnol, Paris, Ediciones Hispanoamericanas.

Real Academia Española (2009): Nueva gramática de la lengua española, Madrid, Espasa-Calpe.

Roegiest, Eugeen (1977): "Hacia una nueva definición de las proposiciones espaciales 'a' y 'en' en español contemporáneo", Romanistisches Jahrbuch, pp. 255-282.

Trujillo, Ramón (1971): "Notas para un estudio de las preposiciones españolas", Thesaurus, 26, 2, pp. 234-279.

Waluch-de la Torre, Edyta (2009): Diccionario teórico-práctico de preposiciones espaciales: aplicación traductológica del español al portugués y al polaco, Varsovia, Instituto de Estudios Ibéricos e Iberoamericanos de la Universidad de Varsovia.

Fecha de recepción: 8 de noviembre de 2017

Fecha de aceptación: 17 de abril de 2018

REVISTA DE FILOLOGÍA ESPAÑOLA (RFE), C, 1. ${ }^{\circ}$, enero-junio, 2020, pp. 59-75 ISSN 0210-9174, eISSN 1988-8538, https://doi.org/10.3989/rfe.2020.003 
